\title{
Crop sensitivity to mesotrione residues in two soils: Field and laboratory bioassays
}

\author{
Ana Pintar ${ }^{1 *}$, Sanja Stipicevic ${ }^{2}$, Zlatko Svecnjak ${ }^{3}$, Klara Baric ${ }^{1}$, Josip Lakic $^{1}$, and Mario Sraka ${ }^{4}$ \\ ${ }^{1}$ University of Zagreb, Faculty of Agriculture, Department of Weed Science, Svetošimunska cesta 25, 10000 Zagreb, Croatia. \\ *Corresponding author (apintar@agr.hr). \\ ${ }^{2}$ Institute for Medical Research and Occupational Health, Ksaverska cesta 2, 10000, Zagreb, Croatia. \\ ${ }^{3}$ University of Zagreb, Faculty of Agriculture, Department of Field Crops, Forages and Grasslands, Svetošimunska cesta 25, \\ 10000 Zagreb, Croatia. \\ ${ }^{4}$ University of Zagreb, Faculty of Agriculture, Department of Soil Science, Svetošimunska cesta 25, 10000 Zagreb, Croatia.
}

Received: 3 April 2020; Accepted: 18 June 2020; doi:10.4067/S0718-58392020000400496

\begin{abstract}
Herbicide residues can potentially injure sensitive crops grown in rotation. Thus, the objective of this study was to evaluate the sensitivity of six replacement crops to mesotrione residues $1 \mathrm{yr}$ after herbicide application. In field bioassay, mesotrione was applied at recommended (144 $\mathrm{g}$ ai ha- $\left.{ }^{-1}\right)$, twofold $\left(288 \mathrm{~g}\right.$ ai ha-1), and fourfold $\left(576 \mathrm{~g}\right.$ ai ha $\left.{ }^{-1}\right)$ rates at two soil types (Gleysol and Fluvisol). In field and laboratory bioassays, mesotrione residual activity was followed for a 21-d period using various measurements of phytotoxicity. No visible injuries to mesotrione residues were observed on oat (Avena sativa L.), rapeseed (Brassica napus L.), soybean (Glycine max [L.] Merr.) and sunflower (Helianthus annuиs L.) in the field bioassay. Although mesotrione residues were not detected by HPLC-UV/DAD analysis, field bioassays indicated their presence due to visible injuries on field pea (Pisum sativum L.) grown in Gleysol soil with twofold and fourfold herbicide treatments. In contrast to other test crop responses, sugar beet exhibited visible injuries in both soils, and consequently, was subjected to laboratory bioassay. With increasing mesotrione rates, the reductions in sugar beet (Beta vulgaris L. var. saccharifera Alef.) fresh weight and total carotenoids content ranged from $6.2 \%$ to $18.7 \%$ and from $4.1 \%$ to $19.4 \%$ in Gleysol, and from $1.1 \%$ to $7.7 \%$ and from $0 \%$ to $11.9 \%$ in Fluvisol, respectively. Since herbicide residues could not often be detected by instrumental analysis, the bioassays seem to be a reliable tool for crop safety assessment.
\end{abstract}

Key words: Field pea, Fluvisol, Gleysol, phytotoxicity, sugar beet.

\section{INTRODUCTION}

Mesotrione (2-(4-methylsulfonyl-2-nitrobenzoyl)cyclohexane-1,3-dione) belongs to the group of triketones, the latest generation of herbicides, which has been extensively used worldwide over the last 20 years to control weeds mainly in maize (Zea mays L.) crop (Mitchell et al., 2001; Carles et al., 2017; Dumas et al., 2017). In Croatia, mesotrione is among the most-frequently used herbicides (Phytosanitary Policy, 2019).

Triketones inhibit the activity of 4-hydroxyphenylpyruvate dioxygenase (4-HPPD), an essential enzyme in the pathway of carotenoid biosynthesis, and are effective at the relatively low rates (100-150 $\mathrm{g} \mathrm{ha}^{-1}$ ) (Mitchell et al., 2001). Mesotrione is highly soluble and stabile in water, while it is considered to be a relatively nonpersistent in soil with a half-life ranging from 2 to $32 \mathrm{~d}$ (Rouchaud et al., 2001; Dyson et al., 2002). Its persistence in soils is primarily pH-dependent and is higher in acidic conditions which reduce the ionization of mesotrione as a weak acid with dissociation constant of 3.12 (Lewis et al., 2016). In addition, the persistence of mesotrione may be affected by soil organic matter and clay fraction (Robinson, 2008). In spite of its nonpersistent nature, there is a number of studies that addressed the herbicide residual activity to sensitive crops grown in rotation (Felix et al., 2007; Riddle et al., 2013a). 
The re-cropping interval in crop rotation is usually determined by the type of crop. If mesotrione is applied at a recommended rate the re-cropping interval should be 24 mo for sugar beet (Beta vulgaris L. var. saccharifera Alef.), pea (Pisum sativum L.), bean (Phaseolus vulgaris L.) and other Phaseolus and Vicia species (Phytosanitary Policy, 2019). For less sensitive crops this interval could be reduced, e.g. to 3 and 10 mo for winter wheat and spring wheat, respectively (Riddle, 2012). However, there is no recommendations available for other important crops widely grown in rotation such as soybean (Glycine max [L.] Merr.), sunflower (Helianthus annuus L.), rapeseed (Brassica napus L.), as well as small grain cereals. Previous research indicated that oat (Avena sativa L.) might be the most sensitive cereal crop to herbicide residues (Forsberg and Reeves, 1995).

Torma et al. (2004) applied mesotrione at rates of 168 and $336 \mathrm{~g}$ ai ha- ${ }^{-1}$ with no phytotoxic effects on tested crops (sugar beet, wheat, rapeseed, barley, pea, sunflower and lettuce) of 1-yr soil mesotrione residues. However, in a similar field experiment at a mesotrione rate of $140 \mathrm{~g}$ ai ha ${ }^{-1}$, Riddle et al. (2013a) observed $8 \%$ to $29 \%$ of visible injuries on sugar beet.

In addition to the rate of applied herbicide, the soil type should be also considered in assessment of herbicide activity in soil. Limited data is available regarding the effect of soil type on mesotrione residual activity to field crops. Felix et al. (2007) found that sensitivity of snapbean (Phaseolus vulgaris L.), cabbage (Brassica oleracea L. var. capitata L.), tomato (Lycopersicon esculentum Mill.), bell pepper (Capsicum annuum L.), cucumber (Cucumis sativus L.) and red clover (Trifolium pratense L.) to mesotrione applied the previous year differed between the locations. In their study soil types were silty clay with $39 \%$ clay, $4.4 \%$ organic matter and $\mathrm{pH} 5.5$ at one location, and silt loam with $12 \%$ clay, $3.0 \%$ organic matter and pH 6.0 at other location. Higher visible injuries of all tested crops were found at location with silty clay soil, which also received lower precipitation compared to location with silt loam soil. The herbicide residues in soil are often determined by instrumental methods such as high-resolution gas or liquid chromatography (Chen et al., 2012; Barchanska et al., 2014; Pang et al., 2016). These methods are used for simultaneous quantification of a broad range of agrocontaminants in various types of matrices. Several cost-effective and time-consuming sample preparation steps, such as analyte extraction, as well as purification, concentration and reconstitution of final extracts, are commonly included prior to analysis. However, in trace analysis instrumental techniques often show insufficient sensitivity for herbicide detection at levels which could still harm the crops in rotation. In addition, soil is a complex heterogenic matrix and even after multiple sampling procedure used it is difficult to obtain a representative soil sample and avoid the scattered results. Compared to instrumental analysis, bioassay methods seem to be more useful tools for collecting data regarding the residual activity of herbicides in soil due to their ability to detect biological hazards of certain substance by inducing and measuring its effects on the test plant (Watson and Checkel, 2005).

The objective of this study was to evaluate the sensitivity of six field crops frequently grown in rotation to the 1-yr residues of mesotrione applied at different rates in two types of soils using field and laboratory bioassays.

\section{MATERIALS AND METHODS}

\section{Field bioassay}

Two identical field trials were set up at two sites with different soil types, Gleysol (45 $51^{\circ} 00^{\prime}$ ' N, 16 $6^{\circ} 10^{\prime} 01^{\prime \prime}$ E) and Fluvisol (4551'04' N, 16²'50' E) (IUSS Working Group WRB, 2015), located in Sasinovecki Lug, north-eastern Croatia. Pedological characterization and adsorption affinity for mesotrione of studied soil types were obtained in our previous study (Pintar et al., 2020). Selected data are presented in Table 1. Both sites were previously cultivated with winter wheat (Triticum aestivum L.) Soils were ploughed at $20 \mathrm{~cm}$ depth in autumn, while seed preparation was in spring just before herbicide spraying. Herbicide mesotrione (2-(4-methylsulfonyl-2-nitrobenzoyl)cyclohexane-1,3dione) was applied using a backpack sprayer in 30 April 2016. Mesotrione (40\% ai; Callisto 480 SC, Syngenta Crop Protection, Basel, Switzerland) was used at three rates: R (144 g ha $\left.{ }^{-1}\right), 2 \mathrm{R}$ (288 $\left.\mathrm{g} \mathrm{ha}^{-1}\right)$ and $4 \mathrm{R}\left(576 \mathrm{~g} \mathrm{ha}^{-1}\right)$, where R was the recommended rate. The untreated plots (non-treated control) were also included in field bioassay. The experimental design was a randomized complete block in three replicates with single plot area of $28 \mathrm{~m}^{2}(2.8 \mathrm{~m} \times 10 \mathrm{~m})$. Experimental area was maintained weed-free using a hand hoe. The following plowing was in the spring (May) of 2017 followed by the seedbed preparation for six tested crops: sunflower (Helianthus annuus L.) 'Apolon', sugar beet (Beta vulgaris L. var. saccharifera Alef.) 'Tesla', field pea (Pisum sativum L.) 'Picar', soybean (Glycine max [L.] Merr.) 'Sivka', rapeseed (Brassica napus L.) 'Turan', and oat (Avena sativa L.) 'Kupa'. All tested crops were sown using automatic seed planter 
(Wintersteiger AG, Ried im Innkreis, Austria) in two rows spaced $25 \mathrm{~cm}$. The sensitivity of crops to 1-yr mesotrione residues in soil was determined $21 \mathrm{~d}$ after sowing (DAS) by visual assessment of phytotoxicity (EPPO, 2014). Data of weather condition were collected from the nearest meteorological station and are presented in Table 2.

Table 1. Pedological and adsorption characteristics of studied surface soils.

\begin{tabular}{|c|c|c|c|c|c|c|c|c|c|c|}
\hline \multirow[b]{2}{*}{ Soil } & \multicolumn{7}{|c|}{ Physicochemical properties } & \multicolumn{3}{|c|}{ Adsorption parameters ${ }^{\mathrm{b}}\left(25^{\circ} \mathrm{C}\right)$} \\
\hline & $\mathrm{pH}\left(\mathrm{H}_{2} \mathrm{O}\right)$ & Humus & $\mathrm{OC}$ & $\mathrm{CEC}$ & Sand & Silt & Clay & Texture class ${ }^{\mathrm{a}}$ & $K_{\mathrm{oc}}$ & $\Delta G^{\circ}$ \\
\hline & & $\%$ & $\%$ & $\mathrm{cmol} \mathrm{kg}^{-1}$ & $\longrightarrow$ & $-\mathrm{cm}$ & - & & & $\mathrm{kJ} \mathrm{mol}^{-1}$ \\
\hline Gleysol & 7.7 & 4.2 & 2.5 & 33.8 & 1.1 & 59.6 & 39.3 & Silty clay loam & 56.4 & -0.83 \\
\hline Fluvisol & 8.2 & 2.7 & 1.3 & 21.8 & 11.6 & 66.9 & 21.5 & Silty loam & 41.8 & 1.51 \\
\hline
\end{tabular}

OC: Organic C; CEC: cation exchange capacity; $K_{\mathrm{oc}}$ : Freundlich constant for mesotrione adsorption normalized to the organic $\mathrm{C}$ content $\left(\mathrm{nmol}^{(1-n)} \mathrm{mL}^{n} \mathrm{~g}^{-1}\right) ; \Delta \mathrm{G}^{\circ}$ Standard Gibbs energy change.

${ }^{\mathrm{a}}$ Husnjak (2014).

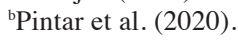

Table 2. Weather data collected at experimental site Sasinovecki Lug during field bioassay compared to 30-yr average.

\begin{tabular}{|c|c|c|c|c|}
\hline Date & $\begin{array}{c}\text { Total } \\
\text { precipitation }\end{array}$ & $\begin{array}{l}\text { Difference from } \\
30 \text {-yr average }\end{array}$ & $\begin{array}{l}\text { Average air } \\
\text { temperature }\end{array}$ & $\begin{array}{l}\text { Difference from } \\
30 \text {-yr average }\end{array}$ \\
\hline & 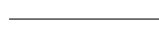 & $\longrightarrow$ & 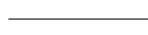 & - \\
\hline \multicolumn{5}{|l|}{2016} \\
\hline May $^{1}$ & 99.0 & +30.4 & 16.1 & +0.2 \\
\hline Jun & 174.0 & +76.8 & 21.1 & +1.7 \\
\hline Jul & 44.5 & -26.9 & 23.4 & +2.3 \\
\hline Aug & 49.5 & -46.7 & 20.8 & +0.4 \\
\hline Sep & 45.7 & -48.4 & 18.6 & +2.4 \\
\hline Oct & 114.0 & +34.5 & 10.4 & -0.6 \\
\hline Nov & 88.9 & +12.9 & 6.8 & +0.9 \\
\hline Dec & 2.8 & -59.9 & -0.4 & -1.1 \\
\hline \multicolumn{5}{|l|}{2017} \\
\hline Jan & 33.3 & -12.2 & -3.2 & -3.1 \\
\hline Feb & 43.1 & +3.5 & 5.2 & +3.0 \\
\hline Mar & 33.6 & -20.5 & 10.0 & +4.6 \\
\hline Apr & 44.3 & -15.2 & 12.4 & +1.1 \\
\hline May $^{2}$ & 45.2 & -23.4 & 17.7 & +1.8 \\
\hline $\mathrm{Jun}^{3}$ & 81.4 & -16.0 & 22.5 & +3.1 \\
\hline
\end{tabular}

${ }^{1}$ Soil treatment with mesotrione.

${ }^{2}$ Soil plowing and crop sowing.

${ }^{3}$ Visual assessment of phytotoxicity.

\section{Instrumental analysis}

Soil samples of $20 \mathrm{~cm}$ depth were collected in May 2017 prior to crop sowing using a probe (Split tube sampler, $\varnothing$ 53 mm, Eijkelkamp, Giesbeek, The Netherlands). Analytical standard of mesotrione (CAS Nr 104206-82-8) 99.9\% purity was purchased from Sigma-Aldrich (St. Louis, Missouri, USA). All other chemicals were of analytical grade purity and supplied by Kemika (Zagreb, Croatia). Microwave-assisted extraction (Mars X, CEM Corp., Matthews, North Carolina, USA) was used for isolation of analyte from $5 \mathrm{~g}$ soil with $30 \mathrm{~mL}$ methanol- $0.1 \mathrm{~mol} \mathrm{~L}^{-1} \mathrm{HCl}$ mixture $(9: 1, v / v)$ at $60{ }^{\circ} \mathrm{C}$ for $5 \mathrm{~min}$. The soil supernatant was evaporated to dryness under a stream of nitrogen, followed by reconstitution with $1 \mathrm{~mL}$ water. The mass concentration of mesotrione in soil extract $\left(\mathrm{ng} \mathrm{mL}^{-1}\right)$ was determined by high-performance liquid chromatography coupled with a photodiode array detector (HPLC-UV/DAD, Varian, Walnut Creek, California, USA) adjusted to $220 \mathrm{~nm}$. The analyte was eluted from Gemini $\mathrm{C}_{18}$ chromatographic column $(5 \mu \mathrm{m}, 250 \mathrm{~mm} \times 4.6 \mathrm{~mm}$, Phenomenex, Torrance, California, USA) by linear gradient of mobile phase (acetonitrile and $0.1 \% O$-phosphoric acid in water) ranging from $5 \%$ to $80 \%$ of acetonitrile over $20 \mathrm{~min}$. The mobile phase flow rate was $1 \mathrm{~mL} \mathrm{~min}{ }^{-1}$ and injected sample volume was $0.1 \mathrm{~mL}$. Quantification was performed using external standards of mesotrione dissolved in water. Analytical recovery was $80 \%$ and detection limit in soil was $5 \mu \mathrm{g} \mathrm{kg}^{-1}$. The mass fraction $\left(\mu \mathrm{g} \mathrm{kg}^{-1}\right)$ of mesotrione in soil samples was recalculated on a dry soil mass. The soil moisture was determined gravimetrically after heating the sample at $105^{\circ} \mathrm{C}$ to a constant mass. 


\section{Laboratory bioassay}

Soil samples were collected from plots planted with sugar beet 21 DAS. Surface soil $(0-20 \mathrm{~cm})$ was sampled using the Eijkelkamp probe. Five soil subsamples from each plot were pulled and homogenized to obtain a representative soil sample. The soils were air-dried for $72 \mathrm{~h}$ and sieved through a $5-\mathrm{mm}$ sieve. The plastic pots $(8 \mathrm{~cm}$ diameter and 10 $\mathrm{cm}$ height) were filled with $200 \mathrm{~g}$ soil and six sugar beet seeds were sown at $1 \mathrm{~cm}$ depth. The experiment design was a randomized complete blocks with three replicates. The soil was moistened up to the field water capacity. Pots were stored in a chamber under controlled conditions $\left(20^{\circ} \mathrm{C} / 15^{\circ} \mathrm{C}\right.$ day/night) for $3 \mathrm{wk}$. Twice a week soils were watered to restore to field capacity.

Visual assessment of phytotoxicity was determined at 7, 14 and 21 DAS using a scale from 0 (no injury) to $100 \%$ (plant death) (EPPO, 2014). The fresh aboveground weight of sugar beet was determined at 21 DAS in pots. The procedure of total carotenoids content determination was previously described (Pintar et al., 2020). Briefly, the plant material was mixed with acetone in a ratio 1:20. The mixture was then homogenized and centrifugated. Supernatant was separated and treatment with acetone was repeated until the green colour of the solid residue was lost. The absorbances of the supernatants were measured spectrometrically at 662,644 and $440 \mathrm{~nm}$. A final concentration of photosynthesis pigments $\left(\mathrm{mg} \mathrm{g}^{-1}\right)$ was calculated using the Holm (1954) and Wettstein (1957) expressions:

$$
\begin{aligned}
& \text { Chlorophyll } \mathrm{a}=9.784 \mathrm{~A}_{662}-0.990 \mathrm{~A}_{644} \\
& \text { Chlorophyll } \mathrm{b}=21.426 \mathrm{~A}_{644}-4.650 \mathrm{~A}_{662} \\
& \text { Chlorophyll } \mathrm{a}+\mathrm{b}=5.134 \mathrm{~A}_{662}+20.436 \mathrm{~A}_{644} \\
& \text { Carotenoids }=4.695 \mathrm{~A}_{440}-0.268(\text { chlorophyll } \mathrm{a}+\mathrm{b})
\end{aligned}
$$

\section{Statistical analysis}

Statistical analysis of the results was performed with the SAS version 8.0 using the Mixed Model Procedure (SAS Institute, Cary, North Carolina, USA). Visual assessments of plant injury were performed by measuring repeatability through time together with both types of soil. Data were subjected to ANOVA, where factors such as soil type, herbicide application rate and assessment time were used as a fixed effect, while replication was a random effect. In data analysis for measurements of fresh aboveground weight and total carotenoid content, the soil type and herbicide rate were considered as a fixed effect, whereas replication was a randomized effect. The LSD test for $\mathrm{P}=0.05$ was used after the significant F-test $(\mathrm{P}=0.05)$ to compare the median values.

\section{RESULTS AND DISCUSSION}

One year after field application, mesotrione residues were analysed in surface soil samples by HPLC-UV/DAD and regardless the dose, the levels were found to be below the detection limit of the method $\left(5 \mu \mathrm{g} \mathrm{kg}^{-1}\right)$. Due to abundant precipitation occurred in the first $2 \mathrm{mo}$ after application $(273 \mathrm{~mm}$ in total, which was increase of 30-70 mm compared to the 30 -yr average of studied sites), the water-soluble mesotrione could be moved toward the deeper soil layers or decomposed during this period. However, the study on mesotrione leaching in soil of different texture (clay, loam, sandy loam and sandy soils; pH 6.4-7.2) showed low mobility of the herbicide applied to corn field at $150 \mathrm{~g}$ ai ha $\mathrm{h}^{-1}$ (residues were mainly found in soil up to $10 \mathrm{~cm}$ at levels in range 6-13 $\mu \mathrm{g} \mathrm{kg}^{-1} 1 \mathrm{mo}$ after the corn harvest) (Rouchaud et al., 2001). In contrast, mesotrione was detected up to $30 \mathrm{~cm}$ of tropical soil layer and its leaching was higher in more alkaline soils with low values of cation exchange capacity (CEC) and OC/clay content (Mendes et al., 2018). Barchanska et al. (2012) indicated that mesotrione is easily degradable and can be eluted from soil with a heavy rainfall $\left(47 \mathrm{~mm} \mathrm{~m}^{-2}\right)$ making the residues detectable in soil only $1 \mathrm{wk}$ after its application at a recommended rate. Degradation of weak acids such as mesotrione is pH-dependent with a rate constant generally higher in alkaline than in acidic soil (van der Linden et al., 2009). In alkaline conditions dissociated mesotrione (anion) has a weak affinity for mostly negatively charged soil surface and thus can be available for biodegradation. On the other hand, the anionic form of mesotrione is more resistant to hydrolysis and photolysis (Barchanska et al., 2016). Therefore, it is possible that under certain scenarios some low levels of mesotrione still persist in alkaline soils with low humus content (low incidence of microorganisms) after 1-yr period of soil treatment with herbicide. Rouchaud et al. (2001) found $10 \mu \mathrm{g} \mathrm{kg}^{-1}$ in soil 6 mo after mesotrione application at $150 \mathrm{~g}$ ai ha' $\mathrm{h}^{-1}$, while Riddle et al. (2013b) reported $8.83 \mu \mathrm{g} \mathrm{kg}^{-1}$ after $1 \mathrm{yr}$ of mesotrione application at $560 \mathrm{~g}^{2}$ ai ha-1. Despite the undetectable 
levels of mesotrione residues, the field bioassay indicated a residual activity on sugar beet and field pea (Table 3), whereas other tested crops (oat, rapeseed, soybean and sunflower) were unaffected. Torma et al. (2004) also reported no phytotoxic effects of mesotrione residues on sunflower after $1 \mathrm{yr}$ of herbicide application at 168 and $336 \mathrm{~g}$ ai ha $^{-1}$. In their study, phytotoxic effects also did not exist on cereals (wheat and barley). Although oat is commonly considered the most sensitive cereal crop to herbicide residues in soil (Forsberg and Reeves, 1995), our results indicated no limitation for growing oat in soils treated with mesotrione application at rates up to $576 \mathrm{~g} \mathrm{ha}^{-1} 1 \mathrm{yr}$ earlier. Riddle et al. (2013b) reported that soybean was the least-sensitive test crop in a conventional (field) residue-carryover study, with injuries observed 21 DAS. In their study, injury symptoms included chlorosis and necrosis of the tissue, but did not cause plant stunting, as well as reduction in fresh weight compared to plant measurements in untreated plots. Up to our knowledge, there is no information available on rapeseed sensitivity to mesotrione residues. Our findings showed no sensitivity of rapeseed crop to $1 \mathrm{yr}$ mesotrione residues even at soil treated with four times higher than recommended rate (Table 3).

The visual assessment of injury showed that sugar beet was more susceptible to mesotrione residues then field pea and that observed plant damage was related to the herbicide application rate and soil type (Table 3). Visible injuries on sugar beet were found in both soils, while field pea was affected only in Gleysol with the highest injury of 5\% at a rate 4R. At the same rate injury of sugar beet was $12 \%$. One year after mesotrione application at 280 and $560 \mathrm{~g}$ ai ha ${ }^{-1}$, Riddle et al. (2013a) observed higher injuries on pea (18\% and 28\%, respectively), but these injuries had no effect on yield. The effect of mesotrione residues on crop damage may be related to weather conditions following herbicide application. Maeghe et al. (2004) indicated that mesotrione loss from soil due to a leaching or degradation processes was favoured in wet seasons, especially in occasions with abundant rainfall within the 2 mo period after herbicide application. In our research, total precipitation in 2 mo following the mesotrione application amounted $273 \mathrm{~mm}$, which was around $65 \%$ higher than $30 \mathrm{yr}$ average (Table 2). In the same period, the air temperatures were also higher than the $30 \mathrm{yr}$ average. It is well-known that warm and humid weather could reduce the herbicide adsorption in soil and thus promote its dissipation (Hurle and Walker, 1980). Therefore, it could be expected that higher crop injuries will be observed during the dry and cold growing seasons.

Based on the results from the field bioassay, sugar beet was selected as the most sensitive test crop for the laboratory bioassay. It was observed that sugar beet grew more slowly under controlled conditions than in field study and that plants were stunted in all pots regardless of the mesotrione rate. Visible injuries at 7, 14, and 21 DAS were similar (data not shown) and their average is shown in Figure 1. Phytotoxic symptoms of sugar beet grown under laboratory conditions followed the same pattern as observed in the field bioassay, with higher sensitivity following the higher herbicide application rate and the heavier soil texture (Gleysol). Sugar beet visible injuries observed in Gleysol ranged from $7 \%$ at a rate $\mathrm{R}$ to $12 \%$ at a rate $4 \mathrm{R}$ (Figure 1). In Fluvisol, sugar beet was unaffected at a rate $\mathrm{R}$, while at rates $2 \mathrm{R}$ and $4 \mathrm{R}$ injuries were in average $2 \%$ and $5 \%$, respectively.

In addition to visible injuries, phytotoxic effect of mesotrione residues in soil was also confirmed by measuring the fresh aboveground weight of sugar beet which differed by soil type and herbicide application rate (Figure 2). In Gleysol, the reduction of fresh weight of sugar beet was $6 \%$ at a recommended rate and $19 \%$ at the highest rate relative to the results obtained in untreated soils. The same phytotoxic parameter measured in Fluvisol showed that sugar beet was not affected by $1 \mathrm{yr}$ residues at a recommended mesotrione rate, while at higher rates the fresh weights were slightly reduced by $6 \%$ and $8 \%$ at $2 \mathrm{R}$ and $4 \mathrm{R}$ rates, respectively, compared to control sample.

Table 3. Effect of 1-yr mesotrione residues on visible injury of tested crops at $21 \mathrm{~d}$ after sowing in two soils. Field bioassay.

\begin{tabular}{|c|c|c|c|c|c|c|c|}
\hline Soil type & Herbicide rate & Oat & Field pea & Rapeseed & Soybean & Sugar beet & Sunflower \\
\hline & $\mathrm{g} \mathrm{ha}^{-1}$ & & & 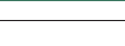 & & & \\
\hline \multirow[t]{4}{*}{ Gleysol } & 0 & 0 & $0 \mathrm{a}$ & 0 & 0 & $0 \mathrm{a}$ & 0 \\
\hline & 144 & 0 & $0 \mathrm{a}$ & 0 & 0 & $5 b$ & 0 \\
\hline & 288 & 0 & $5 b$ & 0 & 0 & $10 \mathrm{~d}$ & 0 \\
\hline & 576 & 0 & $5 b$ & 0 & 0 & $12 \mathrm{e}$ & 0 \\
\hline \multirow[t]{4}{*}{ Fluvisol } & 0 & 0 & $0 \mathrm{a}$ & 0 & 0 & $0 \mathrm{a}$ & 0 \\
\hline & 144 & 0 & $0 \mathrm{a}$ & 0 & 0 & $0 \mathrm{a}$ & 0 \\
\hline & 288 & 0 & 0a & 0 & 0 & $5 b$ & 0 \\
\hline & 576 & 0 & $0 \mathrm{a}$ & 0 & 0 & $7 \mathrm{c}$ & 0 \\
\hline
\end{tabular}

Means followed by the same letter within a column are nonsignificantly different according to Fisher's protected LSD at $\mathrm{P}=0.05$. 
Figure 1. Effect of 1 yr mesotrione residues on visible injury of sugar beet in Fluvisol and Gleysol soils treated with different herbicide rates. Laboratory bioassay.

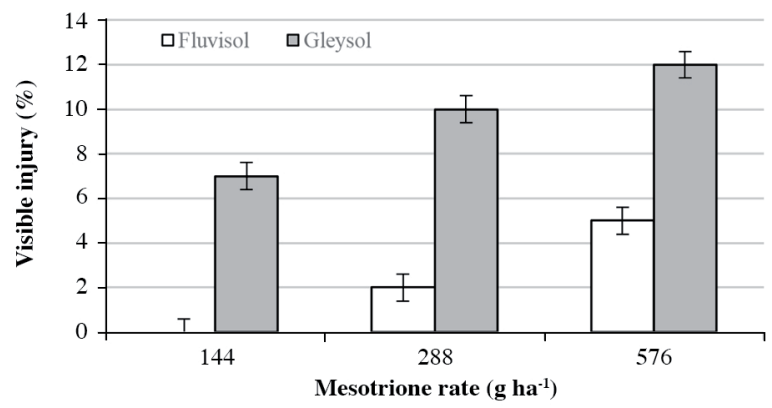

Vertical line indicates the LSD value at $\mathrm{P}=0.05$.

Figure 2. Effect of $1 \mathrm{yr}$ mesotrione residues on fresh weight of sugar beet in Fluvisol and Gleysol soils treated with different herbicide rates. Laboratory bioassay.

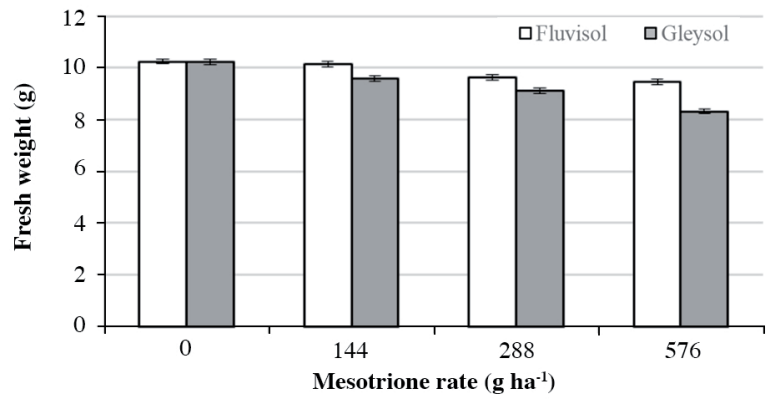

Vertical line indicates the $\mathrm{LSD}$ value at $\mathrm{P}=0.05$.

The total carotenoids contents in sugar beet determined 21 DAS in soil pots containing $1 \mathrm{yr}$ mesotrione residues are shown in Figure 3. The reduction of total carotenoids was not observed in Fluvisol at a recommended rate of mesotrione, but at enhanced rates it amounted 4\% (2R) and 12\% (4R). In Gleysol, total carotenoids content was reduced by $4 \%(\mathrm{R})$ and $19 \%(4 \mathrm{R})$.

Based on the results from field and laboratory bioassays, it was evident that mesotrione residues could be found in soil $1 \mathrm{yr}$ after its application at a recommended rate. These residues, although not detectable by instrumental analysis, could have phytotoxic effect on sensitive crops such as sugar beet. Riddle et al. (2013b) and Allemann and Molomo (2016) found that mesotrione residues as low as 0.43 and $1.6 \mu \mathrm{g} \mathrm{kg}^{-1}$, respectively, may cause significant damage on sensitive crops. Additionally, the results from our bioassays clearly showed that soil type is an important factor for the evaluation of crop sensitivity to mesotrione residues. The phytotoxicity assessment tests used in our research (visible injuries, fresh weight and total carotenoids content) indicated a higher amount of mesotrione residues in Gleysol than in Fluvisol, which suggested a different adsorption affinity of selected soils.

Figure 3. Effect of $1 \mathrm{yr}$ mesotrione residues on total carotenoids content of sugar beet in Fluvisol and Gleysol soils treated with different herbicide rates. Laboratory bioassay.

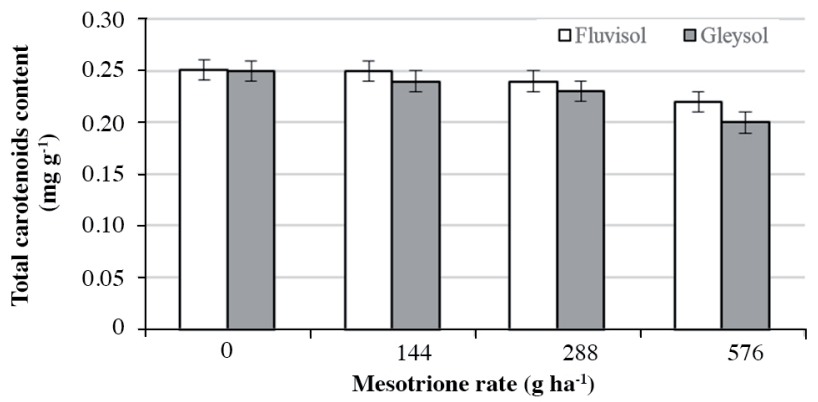

Vertical line indicates the $\mathrm{LSD}$ value at $\mathrm{P}=0.05$. 
Persistence of mesotrione in soil is a result of its interactions with organic, mineral and microbial soil constituents, as well as weather conditions (Dyson et al., 2002). Adsorption is the most significant process which can control the herbicide stability in soil, highly dependent on the pedological characteristics. In sandy soil, $90 \%$ of the applied amount of mesotrione decomposed within 3.6 mo, whereas in heavier soils (loam and clay soils) it remained 4.7 mo (Rouchaud et al., 2001). Adsorption of weak acids such as mesotrione is generally higher in acidic soils, where these species predominantly exist as a neutral molecules rather than anions (Chaabane et al., 2008). The adsorption coefficient $\left(\mathrm{K}_{\mathrm{d}}\right)$ of mesotrione in acidic soil (pH 5.0) was found to be $5.0 \mathrm{~L} \mathrm{~kg}^{-1}$, while in neutral soils it was decreased to $0.13 \mathrm{~L} \mathrm{~kg}^{-1}$ (Dyson et al., 2002). Agricultural soils selected for this study were both slightly alkaline (favouring the mobility of mesotrione as anions) but they differed in texture, CEC value and OC content. Gleysol contained higher fractions of OC (2.5\%) and clay (39.3\%) and showed a higher CEC (33.8 $\left.\mathrm{cmol} \mathrm{kg}^{-1}\right)$ compared to Fluvisol (1.3\% OC, $21.5 \%$ clay, $\left.21 \mathrm{cmol} \mathrm{kg}^{-1} \mathrm{CEC}\right)$. Our previous study confirmed a higher adsorption intensity of mesotrione in Gleysol $\left(\mathrm{K}_{\mathrm{oc}}=56.4\right)$ than in Fluvisol $\left(\mathrm{K}_{\mathrm{oc}}=\right.$ 41.8) (Pintar et al., 2020). A higher adsorption in soil could prevent chemical leaching potential and its availability to soil biota, and therefore it could prolong the herbicide persistence in soil. Furthermore, the interaction mechanisms between the aged mesotrione residues and soil colloids can be more complex than the surface physical adsorption or reversible partition in organic soil fraction, and can alter the chemical structure of soil by formation of intracellular bondings and pore entrapments, all of which may reduce the extraction efficiency prior to instrumental analysis (Gevao et al., 2000). Extraction of these tightly bound residues is determined by the extractant nature and the experimental conditions under which an extraction is carried out such as ionic strength, temperature and co-existence of water molecules. The extraction method used in this study was optimized and tested only for a recently spiked samples (extractable herbicide residues), thus the extraction of bound herbicide residues could have been incomplete. However, low values of Gibbs energy changes calculated for mesotrione adsorption in Gleysol and Fluvisol (Table 1) suggested rather reversible nature of interactions. Therefore, higher but probably reversible mesotrione adsorption in Gleysol than in Fluvisol could be a reason for higher herbicide phytotoxicity to sensitive crop in Gleysol. Additional research of mesotrione persistence in soil should include bioassays with a broad range of soil types to better understand the effect of mesotrione residue phytotoxicity on important replacement crops.

\section{CONCLUSIONS}

The results of this study showed no sensitivity of oat, soybean, rapeseed and sunflower to mesotrione residues in both of the selected soils where herbicide was applied $1 \mathrm{yr}$ before at rates up to $576 \mathrm{~g}$ ai ha ${ }^{-1}$. However, the residual activity was observed in sensitive crops and was related to the soil type and herbicide application rate. It was shown that field pea was susceptible to $1 \mathrm{yr}$ residues in Gleysol when mesotrione was applied at a rate higher than the recommended. Field bioassay demonstrated that sugar beet was the most sensitive test crop to residual activity in both soils. Laboratory bioassay showed that phytotoxic effect of $1 \mathrm{yr}$ mesotrione residues to sugar beet could be found in Gleysol even at a recommended herbicide application rate, as well as in both soils at enhanced rates (higher than $288 \mathrm{~g}$ ai ha $\mathrm{h}^{-1}$ ). In general, residual activity of mesotrione is expected to be higher in Gleysol (silty clay loam) than in Fluvisol (silt loam) soil, also indicating a higher mesotrione persistence in Gleysol due to its higher adsorption affinity than in Fluvisol. Since herbicide residues could not often be detected by instrumental analysis, the bioassays seem to be a reliable tool for crop safety assessment.

\section{ACKNOWLEDGEMENTS}

This research was supported by the Croatian Academy of Sciences and Arts (Nr 10-102/484-1-2016). The authors would like to thank the Department of Soil Science of the Faculty of Agriculture, University of Zagreb, for their cooperation in soil characterization. 


\section{REFERENCES}

Allemann, J., and Molomo, J.M. 2016. Sensitivity of selected dry bean (Phaseolus vulgaris L.) cultivars to mesotrione in a simulated carry-over trial. South African Journal of Plant and Soil 33(3):1-7.

Barchanska, H., Kowalska, A., and Poloczek, B. 2014. Extraction procedures for the study of phytotoxicity and degradation processes of selected triketones in a water ecosystem. Environmental Science and Pollution Research 21:4751-4758.

Barchanska, H., Kulza, A., Krajczewska, K., and Maj, J. 2016. Degradation study of mesotrione and other triketone herbicides on soils and sediments. Journal of Soils and Sediments 16:125-133.

Barchanska, H., Rusek, M., and Szatkowska, A. 2012. New procedures for simultaneous determination of mesotrione and atrazine in water and soil. Comparison of the degradation processes of mesotrione and atrazine. Environmental Monitoring and Assessment 184:321-334.

Carles, L., Joly, M., and Joly, P. 2017. Mesotrione herbicide: efficiency, effects and fate in the environment after 15 years of agricultural use. Clean - Soil, Air, Water 45(9):1700011. doi:10.1002/clen.201700011.

Chaabane, H., Vulliet, E., Calvayrac, C., Coste, C.M., and Cooper, J.F. 2008. Behaviour of sulcotrione and mesotrione in two soils. Pest Management Science 64:86-93.

Chen, X., Li, W., Wu, Q., Chen, W., and Han, L. 2012. Dissipation and residues of the herbicide mesotrione in maize and soil in open field. Bulletin of Environmental Contamination and Toxicology 88:772-775.

Dumas, E., Giraudo, M., Goujon, E., Halma, M., Knhili, E., Stauffert, M., et al. 2017. Fate and ecotoxicological impact of new generation herbicides from the triketone family: An overview to assess the environmental risks. Journal of Hazardous Materials 325:136-156.

Dyson, J.S., Beulke, S., Brown, C.D., and Lane, M.C.G. 2002. Adsorption and degradation of the weak acid mesotrione in soil and environmental fate implications. Journal of Environmental Quality 31:613-618.

EPPO. 2014. Efficacy evaluation of plant protection products. PP 1/135 (4) Phytotoxicity assessment. Bulletin OEPP/EPPO Bulletin 44(3):265-273. European and Mediterranean Plant Protection Organization (EPPO), Paris, France.

Felix, J., Doohan, D.J., and Bruins, D. 2007. Differential vegetable crop responses to mesotrione soil residues a year after application. Crop Protection 26:1395-1403.

Forsberg, R.A., and Reeves, D.L. 1995. Agronomy of oats. p. 223-252. In Welch, R.W. (ed.) The oat crop: Production and utilization. World Crop Series. Springer Netherlands, Dordrecht, Netherlands.

Gevao, B., Semple, K.T., and Jones, K.C. 2000. Bound pesticide residues in soils: a review. Environmental Pollution 108:3-4.

Holm, G. 1954. Chlorophyll mutations in barley. Acta Agriculturae Scandinavica 4(1):457-471.

Hurle, K., and Walker, A. 1980. Persistence and its prediction. p. 83-122. In Hance, R.J. (ed.) Interactions between herbicides and the soil. Academic Press, London, UK.

Husnjak, S. 2014. Sistematika tala Hrvatske. Hrvatska Sveučlišna naklada, Zagreb, Croatia.

IUSS Working Group WRB. 2015. World reference base for soil resources 2014, update 2015. International soil classification system for naming soils and creating legends for soil maps. World Soil Resources Reports Nr. 106. FAO, Rome, Italy.

Lewis, K.A., Tzilivakis, J., Warner, D., and Green, A. 2016. An international database for pesticide risk assessments and management. Human and Ecological Risk Assessment: An International Journal 22(4):1050-1064.

Maeghe, L., Desmet, E.M., and Bulcke, R. 2004. Soil activity and persistence of sulcotrione and mesotrione. Communications in Agricultural and Applied Biological Sciences 69(3):41-48.

Mendes, K.F., dos Reis, M.R., Spokas, K.A., and Tornisielo, V.L. 2018. Assessment of mesotrione leaching applied alone and mixed in seven tropical soils columns under laboratory conditions. Agriculture 8(1):1. doi:10.3390/agriculture8010001.

Mitchell, G., Bartlett, D.W., Fraser, T.E.M., Hawkes, T.R., Holt, D.C., Townson, J.K., et al. 2001. Mesotrione: a new selective herbicide for use in maize. Pest Management Science 57:120-128.

Pang, N., Wang, T., and Hu, J. 2016. Method validation and dissipation kinetics of four herbicides in maize and soil using QuEChERS sample preparation and liquid chromatography tandem mass spectrometry. Food Chemistry 190:793-800.

Phytosanitary Policy. 2019. Ministry of Agriculture. List of registered plant protection products in Croatia. Available at https://fis.mps.hr/TrazilicaSZB/Default.aspx?sid=107\&lan=en-Us (accessed March 2020).

Pintar, A., Stipicevic, S., Lakic, J., and Baric, K. 2020. Phytotoxicity of mesotrione residues on sugar beet (Beta vulgaris L.) in agricultural soils differing in adsorption affinity. Sugar Tech 22:137-142.

Riddle, R.N. 2012. Field and greenhouse bioassay to determine rotational crop response to mesotrione residues. 102 p. PhD thesis. University of Guelph, Department of Plant Agriculture, Guelph, Canada.

Riddle, R.N., O'Sullivan, J., Swanton, C.J., and Van Acker, R.C. 2013a. Crop response to carryover of mesotrione residues in the field. Weed Technology 27(1):92-100.

Riddle, R.N., O'Sullivan, J., Swanton, C.J., and Van Acker, R.C. 2013b. Field and greenhouse bioassays to determine mesotrione residues in soil. Weed Technology 27(3):565-572.

Robinson, D.E. 2008. Atrazine accentuates carryover injury from mesotrione in vegetable crops. Weed Technology 22:641-645.

Rouchaud, J., Neus, O., Eelen, H., and Blucke, R. 2001. Mobility and adsorption of the triketone herbicide mesotrione in the soil of corn crops. Toxicological and Environmental Chemistry 79:211-22. 
Torma, M., Radvany, B., and Hodi, L. 2004. Effect of mesotrione residues on following crops. Journal of Plant Diseases and Protection 19:801-805.

van der Linden, A.M.A., Tiktak, A., Boesten, J.J.T.I., and Leijnse, A. 2009. Influence of pH-dependent sorption and transformation on simulated pesticide leaching. Science of the Total Environment 407:3415-3420.

Watson, P.R., and Checkel, S. 2005. Soil residual herbicide bioassays: Science and practice. p. 71-79. In Van Acker, R.C. (ed.) Soil residual herbicides: Science and management. Topics in Canadian Weed Science, Volume 3. Canadian Weed Science Society, Sainte-Anne-de Bellevue, Québec, Canada.

Wettstein, D. 1957. Chlorophyll letale und der submikroskopische Formwechsel der Plastiden. Experimental Cell Research 12(3):427-434. 